\title{
Influence of shading control patterns on the energy assessment of office spaces
}

\author{
Pedro Correia da Silva ${ }^{\mathrm{a}, *}$ Vítor Leal $^{\mathrm{a}}$, Marilyne Andersen ${ }^{\mathrm{b}}$ \\ ${ }^{a}$ Mechanical Engineering Department, Faculty of Engineering of the University of Porto (FEUP), Rua Dr. Roberto Frias, s.n., $4200-465$ Porto, Portugal

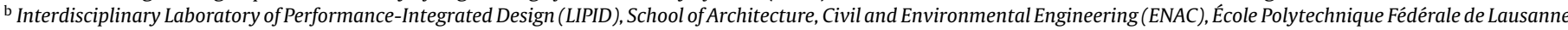 \\ (EPFL), Switzerland
}

\section{A R T I C L E I N F O}

\section{Article history:}

Received 9 November 2011

Received in revised form 24 February 2012

Accepted 2 March 2012

\section{Keywords:}

Visual comfort

Energy efficiency

Lighting

Glare

Building simulation

Behavioral model

\begin{abstract}
A B S T R A C T
This work reviews existing models of control patterns for occupant-shading interactions in office buildings, and studies their influence in terms of energy demand when comparing transparent façade alternatives. It starts by establishing a review of visual comfort criteria in office buildings and of the conditions that prompt occupants to interact with shading devices and electric lighting. Given the large variety of parameters identified as primary variables in the existing literature - hence the variety of conditions considered comfortable depending on the chosen reference - a sensitivity study was carried out based on dynamic simulations. The aim of the study was to characterize the impact of choosing a given shading control model (pattern or strategy) on the calculated overall energy demand for heating, cooling and lighting, as well as the impact on choosing the best-performing transparent façade option for a single-occupant office. The results show that both the calculated energy performance and the ranking of transparent façade alternatives (glazing and shading) often vary very significantly with control patterns considered for the occupant-shading interaction. They further show that, amongst the eleven control strategies that were considered, the behavioral model based on a glare acceptability threshold (expressed as DGI > 20) is the one that, when considered individually, would most reliably express an average ranking from all considered strategies. The implications of these findings are discussed in view of their applicability to energy performance-based façade design choices evaluation as well as to façade design choices.
\end{abstract}

(c) 2012 Elsevier B.V. All rights reserved.

\section{Introduction}

Glazed surfaces have an impact on the energy demand for lighting, heating and cooling of buildings. Combined, they typically account for more than $50 \%$ of the overall energy demand of office buildings in OECD countries and often even as much as over $70 \%$ [1]. The adoption of design methods to select glazing and shading devices should lead to the choice of solutions that ensure a good level of energy efficiency, while guaranteeing esthetical quality and visual comfort to building occupants.

It is common knowledge that building occupants tend to adjust the lighting and shading devices dynamically, as a function of the indoor and outdoor environmental conditions and of the way these conditions might impact their visual comfort perception, in addition to other behavioral motivations independent of their environment. The drivers for this behavior have typically been reported in the forms of workplane illuminance [2-5], luminance [6,7], glare

\footnotetext{
* Corresponding author. Tel.: +35122508 1400 .

E-mail address: pedro.correia.silva@fe.up.pt (P.C. da Silva).
}

indexes $[8,9]$, solar radiation $[6,8,10-13]$ and/or occupation period $[12,14]$.

Although occupant behavior is therefore the result of multiple factors and criteria, the most commonly used methods to evaluate heating and cooling annual demand typically assume that shading devices remain in a fixed position during heating and cooling season. This assumption has in fact been adopted by the building energy regulations of many countries, such as the RSECE in Portugal $[15,16]$ : it assumes that movable shadings are never active during the heating season, and that $70 \%$ of the glazing area is shaded during the cooling season. On the other hand, the EN ISO 13790 [17] recommends a more dynamic method, based on the assumption that the shading devices are used whenever the intensity of the solar irradiation on the window exceeds $300 \mathrm{~W} / \mathrm{m}^{2}$. Regarding electric lighting, the typical assumption in terms of energy consumption evaluation is that it relies on user-defined and fixed daily/weekly/seasonal schedules [18]. As such, it can, again, be considered a non-dynamic approach.

Parameters for deterministic control patterns (static thresholds), including workplane illuminance, glare indexes and solar radiation, are already integrated in simulation frameworks like 


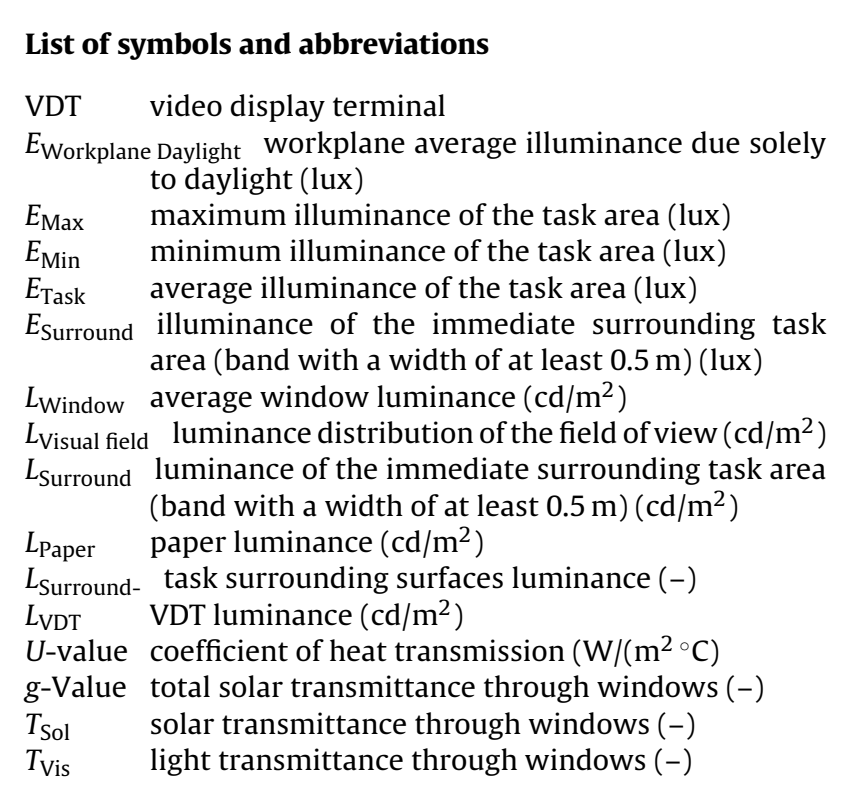

EnergyPlus [19], ESP-r [20] or TRNSYS [21]. The main assumption there is that shading devices or electric lighting are activated whenever the control condition is verified. More sophisticated methods, such as the stochastic model Lightswitch2002 [22] for example, have also been implemented in one dynamic energy simulation platform [23]. This comprehensive model integrates different probabilistic criteria according to the dynamic of the space occupation (arrival, intermediate or at departure).

Given the variety of control parameters and behavioral models, it is of outmost importance to assess how the control patterns for shading devices and electric lighting might affect the resulting energy performance and, consequently, to what extent they might also affect which alternative might be chosen in terms of glazing area and type, or shading device. This study thus aims to assess the impact of considering a given control model instead of another on predicted energy consumption, and to evaluate how consistent the different behavioral models currently used in dynamic simulation are in terms of outcomes and reported control criteria. Toward this end, the paper starts with a literature review of the visual comfort criteria (Section 2) and of the interaction patterns between building occupants and lighting or shading devices (Section 3). To evaluate the impact of choosing a given shading control model on determining the best-performing transparent façade option for a single-occupant office, a sensitivity study was conducted, described in Section 4 and based on EnergyPlus simulations of overall energy consumption for heating, cooling and lighting. The results of this sensitivity study are presented in Section 5 and further analyzed and discussed in Section 6.

\section{Visual comfort criteria}

There are numerous parameters in human psychology that influence the perception of lighting quality. Such parameters include, amongst others, mood, access to a direct view to the outdoors and the occupants' need for privacy, and cannot be objectively measured Some authors argue that, besides enabling visual comfort, "lighting quality" requirements should also comprise proper conditions for task performance and energy-efficiency considerations [24]. There also seems to be a general agreement that the most basic visual comfort requirements relate to levels of illuminance and to how light is distributed in the visual field [24-31]. This chapter presents a bibliographic review of the main physically measurable parameters that drive visual comfort, based on illuminance and luminance distributions.

\subsection{Illuminance}

Illuminance is the quantity underlying visual comfort requirements that is the most often referred to in lighting literature. Table 1 summarizes the recommendations found from different reviewed sources, regarding both absolute illuminance and illuminance ratios (contrast). The table shows that for office buildings, the recommendations for the minimum horizontal illuminance at the workplane vary from 200 to 600 lux for typical writing, typing and reading office tasks. For computer based tasks, however, the recommendations range is between 100 and 300 lux, significantly lower than for paper-based work. The table also presents recommendations for maximum illuminance levels on the workplane ranging between 1280 and 1800 lux, implying that above those levels glare is likely to occur. In addition, table indicates recommendations for the ratio between minimum and maximum workplane illuminance, which should be kept higher than 0.7 , and ratios between horizontal illuminance of the task immediate surrounding areas and illuminance of the task between 0.2 and 0.8 meaning that illuminance of the task shall be higher than the task surroundings.

The type of tasks (computer-based or paper-based) and the source of recommendation ( 8 different ones) lead to variations for reference workplane illuminance of a factor of 3 . Consequently the considered reference for building design and operation will significantly impact the building energy consumption - directly for the electric lighting and indirectly for the space heating and cooling.

\subsection{Luminance distribution}

The luminance distribution affects task visibility, comfort and perception of brightness of a space [27]. Table 2 presents a summary of the literature review addressing absolute luminances and luminance ratios. Recommendations that consider the average luminance of the visual field, wall luminance, ceiling luminance and workplane luminance were all found with highly varying recommended ranges. According to these recommendations, walls and workplane would have to have significantly lower luminances than the ceiling. The recommendations for luminance ratios take

Table 1

Illuminance recommendations for offices.

\begin{tabular}{|c|c|c|}
\hline Source & Parameter & $\begin{array}{l}\text { Recommendations range for comfortable } \\
\text { spaces }\end{array}$ \\
\hline$[25-27,32-37]$ & Workplane illuminance (lux) & $\begin{array}{l}{[100-300] \text { - computer based tasks; }} \\
{[200-600] \text { - paper based tasks; }} \\
1280-1800 \text { - maximum values }\end{array}$ \\
\hline$[25,34]$ & $E_{\text {Min }} / E_{\text {Max Workplane }}$ & $\begin{array}{l}>0.5 \text { - accepted } \\
>0.7 \text { - recommended }\end{array}$ \\
\hline$[27,29,30,34,35]$ & $E_{\text {Surround }} / E_{\text {Task }}$ & {$[0.2-0.8]$} \\
\hline
\end{tabular}


Table 2

Luminance levels recommendations for offices.

\begin{tabular}{|c|c|c|}
\hline Source & Parameter & Recommendations range for comfortable spaces \\
\hline$[30,38]$ & Visual field average luminance $\left(\mathrm{cd} / \mathrm{m}^{2}\right)$ & [20-75] \\
\hline$[25,27,29,30]$ & Wall luminance $\left(\mathrm{cd} / \mathrm{m}^{2}\right)$ & [5-179] maximum value: 1000 \\
\hline$[25,27,35]$ & Ceiling luminance $\left(\mathrm{cd} / \mathrm{m}^{2}\right)$ & [425-850] maximum value: 1000 \\
\hline$[29,30]$ & Workplane luminance $\left(\mathrm{cd} / \mathrm{m}^{2}\right)$ & {$[40-105]$} \\
\hline$[39,40]$ & Glare source luminance $\left(\mathrm{cd} / \mathrm{m}^{2}\right)$ & Maximum value -2500 \\
\hline$[41,42]$ & Window luminance $\left(\mathrm{cd} / \mathrm{m}^{2}\right)$ & Maximum values: [4000-6000] \\
\hline$[25,27,29,30,35]$ & $L_{\text {Paper }} / L_{\text {urround }}$ & {$[0.33-3]$} \\
\hline$[25,27]$ & $L_{\mathrm{VDT}} / L_{\text {urround }}$ & {$[0.33-3]$} \\
\hline
\end{tabular}

into consideration the ratios of paper or VDT luminance and surrounding area luminance, with recommended ratios of at most 1:3 between the task and the immediate surrounding area luminance.

A bibliographic review regarding the compatibility of recommendations referring to luminance found no results. Significant discrepancies might be expected regarding the design options and the energy consumption that would result from the adoption of different recommendations of luminance levels.

One of the undesired effects of inadequate luminance distribution is glare, a visual phenomenon that can be caused by too much brightness or too high luminance ratios in the field of vision. Several indices and metric have been investigated to try to characterize the tendency of given indoor conditions to cause this sensation. The Visual Comfort Probability (VCP) [43], predicts the percentage of population that will accept a given lighting condition as comfortable based on electric lighting. An alternative was developed by the International Commission on illumination (CIE) to produce a consensus glare calculation system and named the Unified Glare Rating (UGR). Its main enhancement compared to VCP was the simpler calculation procedure, which made it ultimately substitute the VCP [44].

For daylighting, which involves wide luminance ranges and potential glare sources, several parameters can be found. One of the simplest is the maximum window luminance, as reported by Platzer [41] and also adopted by EN 14501 [42]. Some specific daylight glare indices were and are still being developed. The daylight glare index (DGI), commonly referred to in the calculation of daylight discomfort glare [45], is based on a mathematical formulation that uses the glare source luminance (average window luminance), the solid angle, the background luminance (average luminance of the field of view, excluding glare source) and the position index. It indicates the degree of discomfort glare due to daylight. Some limitations in its application were identified for the prediction of glare under real sky conditions and for situations where the glare source is non-uniform or fills approximately the whole field of view $[39,44,46]$. As a result Nazzal $[47,48]$ proposed changes to the calculation of the DGI, introducing the new daylight glare index $\left(D_{\mathrm{NI}}\right)$, whose main enhancement consisted of increased accuracy relatively to the DGI formulation. Its adequacy to predict glare sensation has not yet been validated with other independent studies. Another recent index characterizing discomfort glare is the daylight glare probability (DGP) [49]. It intends to express the percentage of people experiencing glare in a given visual condition and is based on the vertical eye illuminance, the glare sources luminance, the solid angle and the position index. It was developed considering several daylighting conditions, analyzing the response of 70 subjects in two different locations, Copenhagen (Denmark) and Freiburg (Germany). The evaluation of experimental results and users response has shown a good correlation between DGP and discomfort glare as subjectively assessed by occupants, better than any of the previously mentioned indices [49]. A notable development is DGP's strong dependency on vertical eye illuminance, much stronger than other tested functions like window luminance, DGI and the CIE glare index [9]. The consideration of the vertical illuminance as a measure of the eye adaptation level represents the main difference of DGP relatively to UGR, DGI and $D G I_{N}$, which consider the background luminance as adaptation parameter, overcoming the difficulty of those indexes to predict glare from large sources.

Table 3 summarizes the main parameters found to characterize glare and the respective recommended ranges for visual comfort. While VCP and UGR were developed for evaluating the level of comfort of indoor environments lit by artificial lighting, DGI and DGP were developed to express the visual comfort under daylight conditions. The consideration of glare indexes during building design and/or operation directly influence the choice of the lamps, daylight systems or indoor environment features and the resulting overall energy consumption.

\subsection{Other parameters related to lighting quality}

Beyond illuminance and luminance distribution considerations, certain lighting qualities that contribute to a space overall lighting performance in terms of occupants satisfaction might also influence visual comfort even though they are not as easy to measure objectively. These would typically include light directionality, its spectral distribution and access to a direct view. Some authors [50-52] also argue that since light "affects the appearance of three-dimensional objects" [51], the potential of lighting to produce shadows and

Table 3

Main parameters to characterize glare and the respective recommended ranges for visual comfort.

\begin{tabular}{|c|c|c|}
\hline Source & Parameter & $\begin{array}{l}\text { Recommendations range for comfortable } \\
\text { spaces }\end{array}$ \\
\hline [27] & Visual comfort probability (VCP) & $\begin{array}{l}\text { >70 - recommended value; } \\
\text { >80 - minimizing discomfort glare; }\end{array}$ \\
\hline$[34,35,39]$ & Unified glare rating (UGR) & $\begin{array}{l}19 \text { - maximum (offices); } \\
\text { >22 - uncomfortable; }\end{array}$ \\
\hline [39] & Daylight glare index (DGI) & $\begin{array}{l}\leq 22 \text { - comfortable; } \\
24-26 \text { - uncomfortable } \\
\geq 28 \text { - intolerable }\end{array}$ \\
\hline$[9,49]$ & $\begin{array}{l}\text { Daylight glare probability (DGP) } \\
\text { (DGP limit value - } 95 \% \text { of } \\
\text { office-time weaker than the } \\
\text { perceived glare sensation) }\end{array}$ & $\begin{array}{l}\leq 0.35 \text { - imperceptible (best class }-\mathrm{A} \text { ) } \\
\leq 0.40 \text { - perceptible (good class }-\mathrm{B}) \\
\leq 0.45 \text { - disturbing }(\text { reasonable class }-\mathrm{C} \text { ) } \\
>0.45 \text { - intolerable }\end{array}$ \\
\hline
\end{tabular}


highlight patterns in a three-dimensional space should be acknowledged as an important aspect of light distribution assessment.

In terms of color and appearance, it is well known that while daylight's spectrum guarantees excellent color rendering [53], the use of some chemical coatings on glazings with low-emissivity or solar protection performance will both reduce the amount of transmitted daylight and modify its spectral distribution. A literature review presented by Dubois [54] refers that, in general, the spectral properties of a glazing directly influences the acceptance of the resulting indoor environment, seeming that occupants tend to prefer the daylight resulting from bronze glazing over the daylight resulting from neutral and blue glazings [55]

Finally, access to a direct view of the outdoor environment has been reported as an important contributor to the visual comfort perception in a room $[42,56,57]$. Occupants also seem to prefer a natural rather than a built or urban view [58]. Recently, further studies and field work have been conducted to better understand the role of the view out (with varying degrees of 'interest') in a space's visual perception and potential for visual discomfort [59,57] and tend to report a positive influence of the view out on perceived visual discomfort. Other tangible variables that are also referred to in the literature as influential in visual comfort perception include the flicker rate of artificial light sources, the type of lighting system (direct versus indirect) and the type of lighting control $[27,30]$.

There is a large range of criteria that are indicated in the literature that affirm to ensure visual comfort or representing occupants preferences in office buildings. Significant differences are found among the criteria, which makes also expect considerable differences in subsequent choices of building design options or in evaluating building energy consumption performance.

\section{Conditions that cause of manual operation of shading devices and electric lighting}

Several reasons have been indicated as potentially motivating factors in the control of shading devices or electric lighting by occupants of office buildings. This section summarizes the conditions that seem to cause a manual operation of shading devices and electric lighting as indicated in the literature.

Tables 4 and 5 identify the criteria that are used to model occupants operation of shading devices (Table 4) or electric lighting (Table 5). The literature review revealed that such criteria were usually based on physical parameters that were either measurable or computable, and involving a strong connection between lighting quality and the stimulus to adjust shading or electric lighting. Some of the criteria straightforwardly use parameters described in Section 2 based on illuminance and/or luminance distributions, while others relate to weather conditions, based on solar radiation and external illuminance.

The occupants' behavior patterns were identified from both field monitoring in buildings and laboratory data. However, most of the reported criteria were based on a limited number of offices in specific locations and in restricted monitoring periods. The use of such criteria therefore requires the exact assessment conditions to be taken into account, making generalization difficult. Most of the criteria indicated in Tables 4 and 5 are static triggering values, with fixed frontier values that characterize a deterministic model. A different approach has also been tried by some authors where occupants' actions are instead characterized by a probability of occurrence $[2,3,6,14]$.

According to Table 4, office building occupants will activate or deactivate the shadings based on three different types of criteria:

(i) quantity of daylight (illuminance) that falls on the workplane; (ii) visual discomfort related to glare, accounted indirectly by window luminances, transmitted solar radiation or directly by daylight glare indexes;

(iii) direct solar radiation, which can create both thermal and visual discomfort.

There is no agreement about which behavioral model or control pattern best predicts occupants actions for each building design and weather conditions, Furthermore, many are formulated in different primary parameters, which makes it difficult to assess their compatibility. Nevertheless, this review suggests the following:

- Solar radiation has been the most cited parameter driving shading control.

- Among the different sources, solar radiation is expressed in different ways, such as direct or global solar radiation, incident or transmitted solar radiation, beam or vertical solar radiation. It is very difficult to assess the compatibility of the different criteria, especially because each criteria was developed under specific research conditions.

- The criteria based on visual discomfort have few citations, probably denoting that the methods to assess glare conditions are insufficiently known or trusted by the academic community not specific to visual comfort studies.

- Activating the shading devices is more dependent of the environmental conditions than deactivating the shadings. The number of studies referring the criteria for deactivating shading devices is very low.

- The majority of criteria indicate deterministic threshold parameters; however the more recent studies report probabilistic correlations for the shading positions adjustments.

As far as the interaction between building occupants and electric lighting is concerned, it has been the object of study for decades with some widely accepted patterns [3,61]. Table 5 presents a review of the criteria for manual control of electric lighting as reported in the literature. Two different patterns can be observed. In the first one, the electric lighting is switched-on during the hours when the office is occupied. According to this model, during the occupation period people rarely switch-off the lights once daylight illuminance levels override the set point for illuminance, and most of the time occupants do not have the perception of the luminaires' state [3]. In a second reported model, the lights are switched-on when the daylight illuminance level is not sufficient to perform tasks. Generally the electric lighting is switched-off when the occupants leave the office.

By observing that the operation of electric lighting is strongly related to illuminance and luminance levels in the rooms, it is reasonable to assume that there is also an indirect connection between the actuation of shading devices and electric lighting. The adjustment of the shadings state (increase of opacity) to control glare will result in a high probability of switching on the lights (if before switched off). Logic would indicate a low chance of the inverse happening i.e. deactivating shading and consequently switch off electrical lighting, but no references were found about this specific behavior.

The manual operation of shading devices and electric lighting has been object of several studies and different conditions were reported as possible options to model the behavior of office building occupants. Twenty models or criteria were found that relate to the manual operation of shading devices and eight models or criteria that relate to the manual operation of electric lighting, with a large diversity of control approaches (control parameters, thresholds, type of criteria and applicability). The indicated conditions are not necessarily compatible amongst each other and might 
Table 4

Review of the criteria for manual control of shading devices in office buildings.

\begin{tabular}{|c|c|c|c|c|c|}
\hline \multirow[t]{2}{*}{ Driving parameter } & \multirow[t]{2}{*}{ Source } & \multirow{2}{*}{$\begin{array}{l}\text { Criteria for adjustment of the shading } \\
\text { position }\end{array}$} & \multicolumn{2}{|l|}{ Action } & \multirow[t]{2}{*}{ Development context } \\
\hline & & & Opening & Closing & \\
\hline \multirow[t]{5}{*}{ Indoor illuminance } & {$[5,37]$} & $\begin{array}{l}\text { Shade actuated if } E_{\text {Workplane Daylight }} \\
\text { higher than } 1800 \text { lux }\end{array}$ & & $x$ & Survey of 16 office buildings. U.K. \\
\hline & {$[2]$} & $\begin{array}{l}\text { Actions on arrival (lower blinds) } \\
\text { Probability of window blind closing as } \\
\text { a function of indoor illuminance and } \\
\text { lower unshaded window fraction } \\
\text { (combined } 5000 \text { lux and } 100 \% \text { result in } \\
\text { a probability of action of } 81 \% \text { ) }\end{array}$ & & $x$ & $\begin{array}{l}\text { Monitoring of } 14 \text { one or two-person } \\
\text { offices during } 7 \text { years. Switzerland }\end{array}$ \\
\hline & [2] & $\begin{array}{l}\text { Actions on arrival (lower blinds) } \\
\text { Probability of window blind opening as } \\
\text { a function of indoor illuminance and } \\
\text { lower unshaded window fraction } \\
\text { (combined } 500 \text { lux and } 0 \% \text { result in a } \\
\text { probability of action of } 50 \% \text { ). }\end{array}$ & $x$ & & $\begin{array}{l}\text { Monitoring of } 14 \text { one or two-person } \\
\text { offices during } 7 \text { years. Switzerland }\end{array}$ \\
\hline & {$[2]$} & $\begin{array}{l}\text { Actions during the presence and at } \\
\text { departure (lower blinds) } \\
\text { Probability of window blind closing as } \\
\text { a function of indoor illuminance and } \\
\text { lower unshaded window fraction } \\
\text { (combined } 5000 \text { lux and } 100 \% \text { result in } \\
\text { a probability of action of } 19 \% \text { ) }\end{array}$ & & $x$ & $\begin{array}{l}\text { Monitoring of } 14 \text { one or two-person } \\
\text { offices during } 7 \text { years. Switzerland }\end{array}$ \\
\hline & {$[2]$} & $\begin{array}{l}\text { Actions during the presence and at } \\
\text { departure (lower blinds) } \\
\text { Probability of window blind opening as } \\
\text { a function of indoor illuminance and } \\
\text { lower unshaded window fraction } \\
\text { (combined } 500 \text { lux and } 0 \% \text { result in a } \\
\text { probability of action of } 16 \% \text { ) }\end{array}$ & $x$ & & $\begin{array}{l}\text { Monitoring of } 14 \text { one or two-person } \\
\text { offices during } 7 \text { years. Switzerland. }\end{array}$ \\
\hline \multirow[t]{4}{*}{ Luminance } & {$[25]$} & $\begin{array}{l}\text { Inferred that shading is actuated if any } \\
L_{\text {Visual field }} \text { higher than } 1000 \mathrm{~cd} / \mathrm{m}^{2}\end{array}$ & & $x$ & Undetermined \\
\hline & [41] & $\begin{array}{l}\text { Inferred that shading is actuated if } \mathrm{L} \\
\text { Window higher than } 5000 \mathrm{~cd} / \mathrm{m}^{2}\end{array}$ & & $x$ & Undetermined \\
\hline & {$[6]$} & $\begin{array}{l}\text { Actions on arrival } \\
\text { Probability of window blind closing as } \\
\text { a function of maximum window } \\
\text { luminance ( } 4466 \mathrm{~cd} / \mathrm{m}^{2} \text { for a } \\
\text { probability of action of } 50 \%), \\
\text { background luminance }\left(225 \mathrm{~cd} / \mathrm{m}^{2} \text { for a }\right. \\
\text { probability of action of } 50 \%), \text { and } \\
\text { average window luminance }\left(890 \mathrm{~cd} / \mathrm{m}^{2}\right. \\
\text { for a probability of action of } 50 \%),\end{array}$ & & $x$ & $\begin{array}{l}\text { Survey of } 2 \text { office buildings offices } \\
\text { during } 5 \text { months. California, U.S. }\end{array}$ \\
\hline & [7] & $\begin{array}{l}\text { Shading actuated if } L_{\text {Window }} \text { higher than } \\
1800 \mathrm{~cd} / \mathrm{m}^{2}\end{array}$ & & $x$ & $\begin{array}{l}\text { Monitoring of } 8 \text { one person offices } \\
\text { during } 7 \text { months. France }\end{array}$ \\
\hline \multirow[t]{3}{*}{ Glare indexes } & {$[8]$} & Shading actuated if DGI higher than 20 & & $\times$ & undetermined \\
\hline & [39] & $\begin{array}{l}\text { Inferred that shading is actuated if DGI } \\
\text { higher than } 24\end{array}$ & & $x$ & undetermined \\
\hline & {$[9,49]$} & $\begin{array}{l}\text { Shading actuated if DGP higher than } \\
40 \%\end{array}$ & & $x$ & $\begin{array}{l}\text { Experimental study and occupants } \\
\text { survey (70subjects). Denmark and } \\
\text { Germany }\end{array}$ \\
\hline \multirow[t]{7}{*}{$\begin{array}{l}\text { Solar radiation and } \\
\text { external illuminance }\end{array}$} & [13] & $\begin{array}{l}\text { Shade actuated if intensity of direct } \\
\text { normal solar radiation hitting the } \\
\text { occupants higher than } 233 \mathrm{~W} / \mathrm{m}^{2}\end{array}$ & & $x$ & Undetermined \\
\hline & [8] & $\begin{array}{l}\text { Shade actuated if transmitted direct } \\
\text { solar radiation (through the } \\
\text { transparent façade) higher than } \\
94.5 \mathrm{~W} / \mathrm{m}^{2}\end{array}$ & & $x$ & Undetermined \\
\hline & {$[10,17]$} & $\begin{array}{l}\text { Shading actuated if vertical solar } \\
\text { irradiation higher than } 300 \mathrm{~W} / \mathrm{m}^{2}\end{array}$ & & $x$ & Undetermined \\
\hline & {$[11]$} & $\begin{array}{l}\text { Shading actuated if the direct solar } \\
\text { radiation that hits the workplace } \\
\text { higher than } 50 \mathrm{~W} / \mathrm{m}^{2} \text { (considering a } \\
\text { specified dept into the room of } 1 \mathrm{~m} \text { ) }\end{array}$ & & $x$ & $\begin{array}{l}\text { Monitoring and occupants survey of } 4 \\
\text { office buildings during } 3 \text { weeks. Japan }\end{array}$ \\
\hline & {$[4]$} & $\begin{array}{l}\text { Shading actuated if direct sunlight } \\
\text { higher than } 50 \mathrm{~W} / \mathrm{m}^{2} \text { and solar gains } \\
\text { higher than } 50 \mathrm{klux}\left(450 \mathrm{~W} / \mathrm{m}^{2}\right)\end{array}$ & & $x$ & $\begin{array}{l}\text { Monitoring of } 10 \text { one and two-person } \\
\text { offices during } 9 \text { months. Germany }\end{array}$ \\
\hline & [4] & $\begin{array}{l}\text { Shading actuated if illuminance on } \\
\text { external façade higher than } 25 \mathrm{klux}\end{array}$ & $x$ & & $\begin{array}{l}\text { Monitoring of } 10 \text { one and two -person } \\
\text { offices during } 9 \text { months. Germany }\end{array}$ \\
\hline & [6] & $\begin{array}{l}\text { Actions on arrival } \\
\text { Probability of window blind closing as } \\
\text { a function of transmitted vertical solar }\end{array}$ & & $x$ & $\begin{array}{l}\text { Measurements and occupants survey } \\
\text { of } 2 \text { office buildings offices during } \\
5 \text { months. California, U.S. }\end{array}$ \\
\hline
\end{tabular}
radiation $\left(13 \mathrm{~W} / \mathrm{m}^{2}\right.$ for a probability of action of $50 \%$ ) 
Table 4 (Continued)

\begin{tabular}{|c|c|c|c|c|c|}
\hline \multirow[t]{2}{*}{ Driving parameter } & \multirow[t]{2}{*}{ Source } & \multirow{2}{*}{$\begin{array}{l}\text { Criteria for adjustment of the shading } \\
\text { position }\end{array}$} & \multicolumn{2}{|l|}{ Action } & \multirow[t]{2}{*}{ Development context } \\
\hline & & & Opening & Closing & \\
\hline & {$[60]$} & $\begin{array}{l}\text { Mean shade deployment degree } \\
\text { (m.s.d.d.) as a function of incident } \\
\text { vertical solar irradiation (South } \\
250 \mathrm{~W} / \mathrm{m}^{2} \mathrm{~m} . \text {.d.d. }=75 \% \text {; North } \\
250 \mathrm{~W} / \mathrm{m}^{2} \mathrm{~m} . \text { s.d.d. }=13 \% \text {; South-west } \\
\text { and south-east } \\
250 \mathrm{~W} / \mathrm{m}^{2} \text { m.s.d.d. }=62 \% \text {; North-west } \\
\text { and north-east } 250 \mathrm{~W} / \mathrm{m}^{2} \text { m.s.d.d. }=19 \% \text {; } \\
\text { West and east } 250 \mathrm{~W} / \mathrm{m}^{2} \text { m.s.d.d. }=50 \% \text { ) }\end{array}$ & $x$ & $x$ & $\begin{array}{l}\text { Monitoring of } 5 \text { office buildings ( } 163 \\
\text { workplaces) during 9-14 months. } \\
\text { Austria }\end{array}$ \\
\hline
\end{tabular}

significantly impact the overall energy consumption of office buildings when used in integrated building simulation.

\section{Sensitivity analysis for an office case study}

The literature review from the previous sections showed that there are different control models of how people interact with shading devices and with electric lighting. These interactions in turn influence building performance in terms of their energy demand for heating, cooling and artificial lighting. It is therefore important to assess how the choices of behavioral models might influence the forecasted energy demand. It is also important to assess whether the differences in energy consumption prediction resulting from the selection of a behavioral model have an impact on the subsequent ranking of design alternatives for the transparent façade elements (e.g. the glazing type, the shading device or even the area of transparent surface). If this is the case, then increasing the robustness of existing behavioral models - or developing a more robust method to choose amongst the models - would become a priority for reliable energy simulations.

So as to assess the impact of the behavioral model choice (regarding interaction with shading devices and electric lights) on the energy performance of buildings, a detailed study was performed taking as reference a single-occupant office room located in Porto, Portugal. Porto is located at the latitude of $41^{\circ} \mathrm{N}$ and has an European Atlantic Climate, with 1610 heating degree-days at base temperature of $20^{\circ} \mathrm{C}$. The room (Fig. 1) was modeled in whole-building simulation software, and different transparent façade design options were tested. A more detailed description of the building and room are presented in Section 4.1.

Fig. 2 summarizes the framework of the conducted simulations. This framework included:Three scenarios regarding the result of climate and building characteristics: a heating-dominated scenario, a cooling-dominated scenario and one with balanced heating and cooling. The differentiation was achieved by increasing the level of thermal insulation of the envelope (to achieve a coolingdominated scenario) or by lowering the air temperature of the climate file (to achieve a heating-dominated scenario);For each of the scenarios described in (i), the analysis of four options regarding the choice of glazing, four options regarding the shading devices, and four options regarding the area of transparent façade;The energy demand with each of the glazing, shading or window areas described in (ii) was calculated for 11 behavioral models of the interaction between the occupants and the shading devices.

Table 5

Criteria of manual control of electric lighting in office buildings.

\begin{tabular}{|c|c|c|c|c|c|}
\hline \multirow{2}{*}{$\begin{array}{l}\text { Driving } \\
\text { parameter }\end{array}$} & \multirow[t]{2}{*}{ Author } & \multirow{2}{*}{$\begin{array}{l}\text { Criteria for adjustment of the electric lighting } \\
\text { state }\end{array}$} & \multicolumn{2}{|l|}{ Action } & \multirow[t]{2}{*}{ Development context } \\
\hline & & & Switching-on & Switching-off & \\
\hline \multirow[t]{4}{*}{ Illuminance } & {$[61]$} & $\begin{array}{l}\text { Probability of lights being switched on } \\
\text { function of external total illuminance (in a } \\
\text { multi-person office) ( } 36 \text { klux for a probability } \\
\text { of action of 50\%) }\end{array}$ & $x$ & & $\begin{array}{l}\text { Monitoring of } 3 \text { multi-person } \\
\text { offices during } 6 \text { months. U.K. }\end{array}$ \\
\hline & [3] & $\begin{array}{l}\text { Actions on arrival } \\
\text { Probability of lights being switched on as a } \\
\text { function of indoor illuminance ( } 67 \text { lux for a } \\
\text { probability of action of } 50 \% \text { ) }\end{array}$ & $x$ & & $\begin{array}{l}\text { Monitoring of } 3 \text { multi-person } \\
\text { offices during } 6 \text { months. U.K. }\end{array}$ \\
\hline & {$[4]$} & $\begin{array}{l}\text { Actions on arrival } \\
\text { Probability of lights being switched on as a } \\
\text { function of indoor illuminance ( } 170 \text { lux for a } \\
\text { probability of action of } 2 \% \text { ) }\end{array}$ & $\times$ & & $\begin{array}{l}\text { Monitoring of } 10 \text { one or } \\
\text { two-person offices during } \\
9 \text { months. Germany }\end{array}$ \\
\hline & {$[4]$} & $\begin{array}{l}\text { Actions during the presence } \\
\text { Probability of lights being switched on as a } \\
\text { function of indoor illuminance ( } 67 \text { lux for a } \\
\text { probability of action of } 50 \% \text { ) }\end{array}$ & $\times$ & & $\begin{array}{l}\text { Monitoring of } 10 \text { one or } \\
\text { two-person offices during } \\
9 \text { months. Germany }\end{array}$ \\
\hline \multirow[t]{2}{*}{ Luminance } & [27] & $\begin{array}{l}\text { Inferred that electric lighting state is adjusted } \\
\text { if } L_{\text {Ceiling }} \text { higher than } 850 \mathrm{~cd} / \mathrm{m}^{2}\end{array}$ & & $\times$ & Occupants preferences \\
\hline & [35] & $\begin{array}{l}\text { Inferred that electric lighting state is adjusted } \\
\text { if } L_{\text {Ceiling }} \text { higher than } 500 \mathrm{~cd} / \mathrm{m}^{2}\end{array}$ & & $x$ & Occupants preferences \\
\hline \multirow[t]{2}{*}{ Period of absence } & {$[14]$} & $\begin{array}{l}\text { Probability of lights being manually switched } \\
\text { off function of length of occupancy absence } \\
\text { from the workstation (range 1-2 h for a } \\
\text { probability of action of } 38 \% \text { ) }\end{array}$ & & $\times$ & $\begin{array}{l}\text { Monitoring of } 63 \text { one person } \\
\text { offices during } 11 \text { months. } \\
\text { Winscosin, U.S. }\end{array}$ \\
\hline & {$[12,60]$} & $\begin{array}{l}\text { Probability of lights being manually switched } \\
\text { off function of length of occupancy absence } \\
\text { from the workstation ( } 125 \text { min for a } \\
\text { probability of action of } 50 \%)\end{array}$ & & $x$ & $\begin{array}{l}\text { Monitoring of } 5 \text { office buildings } \\
\text { (163 workplaces) during } 9 \text { to } \\
14 \text { months. Austria }\end{array}$ \\
\hline
\end{tabular}




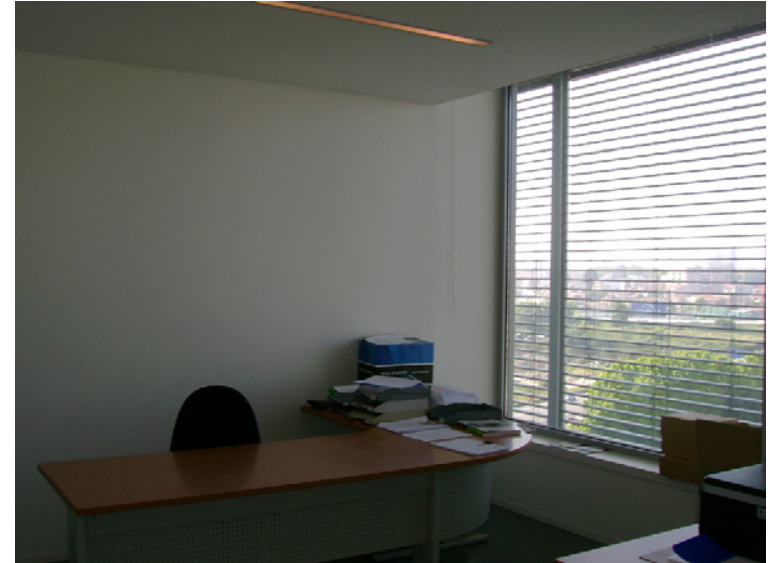

Fig. 1. Case study - single office room.

For each combination of scenario and design alternative, the electric lighting and space heating and cooling needs were calculated through dynamic building simulation, using the Porto's hourly weather data file. In each of the simulations electric lighting was considered to be controlled with an ideal dimming complementary to natural lighting, in order to ensure 500 lux on the workplane during the occupied period.

\subsection{Geometry and envelope}

The office room is $5.3 \mathrm{~m}$ long and $3.0 \mathrm{~m}$ wide, resulting in a floor area of $16 \mathrm{~m}^{2}$. The room is daylit by a south oriented window of $5.5 \mathrm{~m}^{2}$, which fills about $65 \%$ of the office south façade. The only elements of the office envelope that contact with the outdoors are the south façade $\left(8.5 \mathrm{~m}^{2}\right)$. The external walls have a $U$-value of $0.67 \mathrm{~W} / \mathrm{m}^{2}{ }^{\circ} \mathrm{C}$. All the other elements of the office envelope in contact with other office rooms were assumed to be at the same indoor environmental conditions. The window is shaded by external Venetian blinds. The room occupancy was defined as 1 person from 9 to $13 \mathrm{~h}$ and from 14 to $19 \mathrm{~h}$, the artificial lights electric power as $10 \mathrm{~W} / \mathrm{m}^{2}$ from 9 to $19 \mathrm{~h}$, the office equipments electric power as $10 \mathrm{~W} / \mathrm{m}^{2}$ from 9 to $19 \mathrm{~h}$, and the fresh air ventilation rate as $1 \mathrm{ach}$ from 9 to $19 \mathrm{~h}$ and $0.5 \mathrm{ach}$ from 0 to $9 \mathrm{~h}$ and from 19 to $24 \mathrm{~h}$.

The assessment of the office overall energy consumption (for lighting, heating and cooling) was performed considering different design alternatives for the transparent façade: glazing types, window to wall ratios and shading devices.

As far as glazings are concerned, the range of analyzed alternatives consisted of four different double layer glazing windows ( $6 \mathrm{~mm}-12 \mathrm{~mm}-6 \mathrm{~mm}$ ), whose main properties are shown in Table 6. These exhibit similar coefficients of heat transmission but different optical values, covering the overall range of existing glazing optical characteristics, from a dark solar control glazing (G1) to a very clear glazings (G4) [62]. It was considered that all of these glazings have very high color rendering indexes and therefore, neutral impact on color perception.

Four different values of window to wall ratio (WWR - percentage of the exterior wall area which is made of window) were tested, $20 \%, 40 \%, 65 \%$ and $90 \%$, always keeping the center of window at the occupants view level. Table 9 shows the properties of the considered WWR alternatives.

The properties of the four options for the external venetian blinds considered for this study were taken from the calculation tool WIS [63] and are presented in Table 8. Similarly to the glazings, the four shading device options were selected based on their transmittance values.

As mentioned in the introduction of this section, a sensitivity analysis of Tables 6-8 was performed three times: first in a scenario where the annual cooling demand is significantly higher that the heating demand, second with two demands that are of the same order of magnitude and third with a cooling demand significantly lower than the heating demand. The cooling-dominated scenario corresponds to the "as built" in Porto, considering one exterior wall, South-oriented, with an $U$-value of $0.48 \mathrm{~W} /\left(\mathrm{m}^{2}{ }^{\circ} \mathrm{C}\right)$. The transformation toward "balanced heating and cooling" was achieved by considering walls and roof as external $\left(U\right.$-values of $0.48 \mathrm{~W} /\left(\mathrm{m}^{2}{ }^{\circ} \mathrm{C}\right)$ and $0.27 \mathrm{~W} /\left(\mathrm{m}^{2}{ }^{\circ} \mathrm{C}\right)$, respectively), which increased the heat losses toward outdoors; and finally, to achieve a heating-dominated scenario, the envelope of the balanced heating and cooling scenario was considered however the climate file was changed by arithmetically removing $8^{\circ} \mathrm{C}$ from the outdoor temperature in the climate file for all hours of the year. This virtual climate file option was considered preferable to changing the climate location, as the latter would affect also the daylighting availability and consequently decrease the comparability of the results.

\subsection{Behavioral models/control strategies of the shading devices}

The main objective of this work is to assess the impact that behavioral models and associated control patterns for shading devices have in terms of energy demand for heating, cooling and electric lighting. Therefore, following the review presented in Sections 2 and 3, a comprehensive set of behavioral models was selected to be subjected to a sensitivity analysis. The set is essentially the one already presented in Table 4, plus four steady-state strategies. They are all summarized in Table 9 as a single list.

The strategies S0 (blinds totally inactive) and S1 (blinds totally active) are not representative of real patterns of blinds control but were considered as limit conditions.

S2 and S3 are the strategies most often considered in practice by building designers and consultants when assessing the energy performance of buildings. They sometimes are imposed by the calculation methods adopted by national regulations [15].

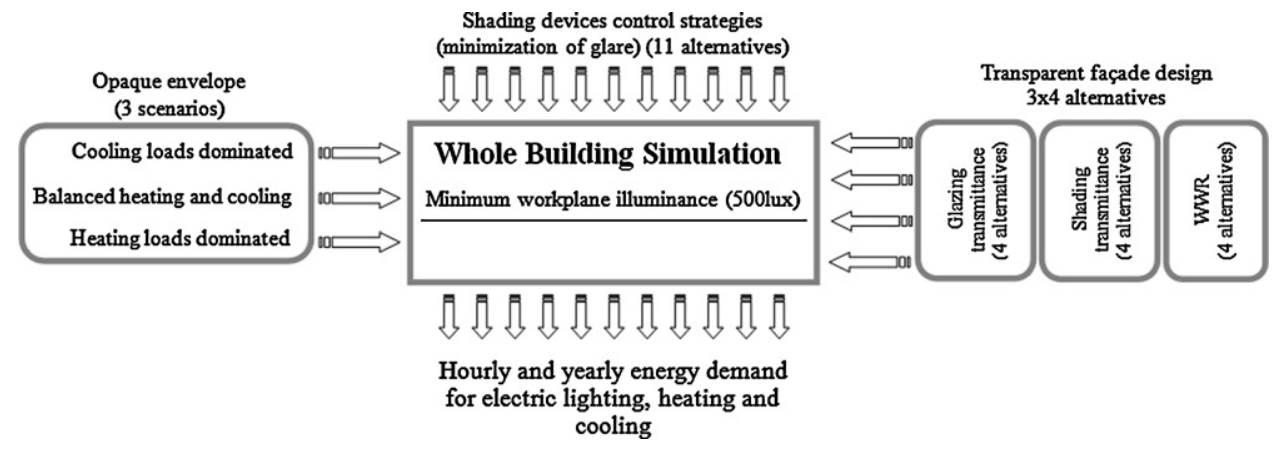

Fig. 2. Summary of the framework of simulations. 
Table 6

Transparent façade - glazing types alternatives.

\begin{tabular}{|c|c|c|c|c|c|c|}
\hline & \multicolumn{4}{|l|}{ Glazing properties } & \multirow[t]{2}{*}{ Shading device } & \multirow[t]{2}{*}{ WWR } \\
\hline & $U$-value $\mathrm{W} /\left(\mathrm{m}^{2}{ }^{\circ} \mathrm{C}\right)$ & $g$-Value (\%) & $T_{\text {Sol }}(\%)$ & $T_{\mathrm{Vis}}(\%)$ & & \\
\hline G1 & 1.57 & 20 & 3 & 6 & \multirow{4}{*}{ Shad3 $\left(T_{\mathrm{Sol}}=24.0 \% ; T_{\mathrm{Vis}}=24.9 \%\right)$} & \multirow{4}{*}{ WWR3 (65\%) } \\
\hline G2 & 1.57 & 30 & 15 & 24 & & \\
\hline G3 & 1.57 & 51 & 41 & 43 & & \\
\hline G4 & 1.58 & 75 & 63 & 79 & & \\
\hline
\end{tabular}

Table 7

Transparent façade - WWR alternatives.

\begin{tabular}{|c|c|c|c|}
\hline & WWR (\%) & Glazing type & Shading device \\
\hline WWR1 & 20 & \multirow{4}{*}{$\mathrm{G} 3\left(T_{\mathrm{Sol}}=41.0 \%, T_{\mathrm{Vis}}=42.0 \%\right)$} & \multirow{4}{*}{ Shad3 $\left(T_{\text {Sol }}=24.0 \% ; T_{\text {Vis }}=24.9 \%\right)$} \\
\hline WWR2 & 40 & & \\
\hline WWR3 & 65 & & \\
\hline WWR4 & 90 & & \\
\hline
\end{tabular}

The strategies S4, S5, S6 and S7 are based on the assumptions that occupants activate external blinds each time they are visually uncomfortable, and that they turn the blinds inactive again as soon as the occupants are comfortable without the action of the blinds. Two different threshold values for the DGI were considered (16 and 22 ). Recognizing that DGI is highly dependent on the occupant view angle, two different positions were considered for the occupant: a standard occupant position that would represent a view angle parallel to the window $\left(0^{\circ}\right)$ and a second one which considers the occupant slightly turned toward the window (view angle of $20^{\circ}$ with the window plane).

The strategies S8 and S9 make use of the vertical solar radiation transmitted through the window to adjust blinds positions. The value of beam (direct normal) plus the diffuse radiation is calculated for each simulation time-step and the blind is fully lowered if the transmitted solar radiation through the window (without the effect of the shading device) is higher than a specified solar radiation value $\left(100 \mathrm{~W} / \mathrm{m}^{2}\right.$ in $\mathrm{S} 8$ and $200 \mathrm{~W} / \mathrm{m}^{2}$ in S9). For each glazing type the glazing solar transmittance was considered to find the incident solar radiation that shall be used to trigger the blind position.

The strategies S10 and S11 rely on the user behavioral control model Lightswitch [22,64]. This model is integrated in DAYSIM [65]. The two different types of user behavior were tested: the active (S10) and the passive (S11). They both will partly close the shading devices during the day to avoid direct sunlight higher than $50 \mathrm{~W} / \mathrm{m}^{2}$ impinging the working space. Once closed, they will remain in that state. The main difference between both types is that the active type fully opens the shading devices when arriving in the morning, while the passive type does not do this.

\subsection{Estimation of the overall energy consumption}

All simulations were performed with the EnergyPlus building simulation software [19]. It allows for the direct implementation of the control strategies S0 to S9. For strategies S10 and S11, the DAYSIM [65] output text files (hourly values of indoor illuminance, electric lighting and shading devices state) were used as inputs to
EnergyPlus to specify the state of the blind at each hour of the year, thus ensuring the connection of both algorithms. The thermal part was treated by EnergyPlus alone.

All simulations were performed with an ideal dimming strategy to control electric lighting to prevent possible overlapping between manual occupants' models to control electric lighting and models to control shading devices. This means that the light power of the office room is continuously adjusted by a virtual real-time idealdimming system, which reduces the electric power proportionally to the amount of incident daylight to guarantee a minimum of 500 lux on of the workplane, positioned $2 \mathrm{~m}$ away from the window. The calculation of the daylight contribution is based on Daylight Factors for a standard overcast sky and on indoor and outdoor illuminance ration for clear sky conditions with 20 different representative sun positions of one indoor reference point $[66,67]$. The models using the control strategies S10 and S11 use the indoor illuminance calculated by DAYSIM, as referred previously. DAYSIM has an integrated RADIANCE algorithm coupled with a daylight coefficient approach to estimate daylight illuminances [65].

For each simulation, the total annual energy consumption for electric lighting, ambient heating and ambient cooling was evaluated based on the building design options, the control strategies and the boundary conditions described previously. To estimate the final energy consumption for space heating and cooling the indoor temperature was assumed to be controlled during office room working hours (9-19h), and kept at a minimum of $20^{\circ} \mathrm{C}$ during the heating season and a maximum of $24^{\circ} \mathrm{C}$ during the cooling season. The energy consumption is computed in the form of electricity, assuming that the heating and cooling are provided by a reversible heat pump system with a seasonal COP of 4 and a EER of 3, respectively.

\section{Results}

\subsection{Cooling dominated scenario}

In the context of the cooling-dominated scenario, Fig. 3 shows the annual energy consumption of the office room, for the four glazing alternatives G1 to G4 presented earlier in Table 6, under each

Table 8

Transparent façade - shading devices alternatives.

\begin{tabular}{|c|c|c|c|c|}
\hline & \multicolumn{2}{|c|}{ Shading device properties } & \multirow[t]{2}{*}{ Glazing type } & \multirow[t]{2}{*}{ WWR } \\
\hline & $T_{\text {Sol }}(\%)$ & $T_{\mathrm{Vis}}(\%)$ & & \\
\hline Shad1 (venetian blinds) & 11.9 & 11.9 & \multirow{4}{*}{$\mathrm{G} 3\left(T_{\mathrm{Sol}}=41 \%, T_{\mathrm{Vis}}=42 \%\right)$} & \multirow{4}{*}{ WWR3 (65\%) } \\
\hline Shad2 (venetian blinds) & 16.8 & 17.7 & & \\
\hline Shad3 (venetian blinds) & 24.0 & 24.9 & & \\
\hline Shad4 (venetian blinds) & 29.5 & 31.7 & & \\
\hline
\end{tabular}


Table 9

Behavioral models/Shading devices control strategies to be considered in the sensitivity analysis.

\begin{tabular}{ll}
\hline S0 & No shading (shading fully open all year round) \\
S1 & Shading is $100 \%$ active from January to December \\
S2 & Shading is $70 \%$ active from April to September \\
S3 & Shading is $100 \%$ active from April to September \\
S4 & Shading is active if DGI $>20(\mathrm{GI}>16), 0^{\circ}$ (view direction parallel \\
& to window) \\
S5 & Shading is active if DGI $>20(\mathrm{GI}>16), 20^{\circ}$ (view direction $20^{\circ}$ \\
& toward window) \\
S6 & Shading is active if DGI $>24(\mathrm{GI}>22), 0^{\circ}$ (view direction parallel \\
& to window) \\
S7 & Shading is active if DGI $>24(\mathrm{GI}>22), 20^{\circ}$ (view direction $20^{\circ}$ \\
& toward window) \\
S8 & Shading is active if transmitted vertical beam plus diffuse solar \\
& radiation $(\mathrm{SRT})>100 \mathrm{~W} / \mathrm{m} 2$ \\
S9 & Shading is active if SRtr $>200 \mathrm{~W} / \mathrm{m} 2$ \\
S10 & Shading is active if direct sunlight that hits the workplane \\
& $>50 \mathrm{~W} / \mathrm{m} 2$, active user $($ Lightswitch) \\
S11 & Shading is active if direct sunlight that hits the workplane \\
& $>50 \mathrm{~W} / \mathrm{m} 2$, passive user $($ Lightswitch) \\
\hline
\end{tabular}

of the 12 shading control strategies S0 to S11 described in Table 9. The energy consumption for each scenario is presented in $\mathrm{kWh}$ per year per $\mathrm{m}^{2}$ of office floor area (Fig. 4).

Fig. 5 shows the results for the four shading alternatives presented in Table 7, while Fig. 6 shows the results for the four alternatives of WWR described in Table 8.

In cooling-dominated scenario, results show that different behavioral models result in different choices of a "best design alternative". The differences are most noticeable for the choice of glazing alternatives and WWR alternatives, higher variations of overall energy consumption are also observed when compared to the energy consumption associated with shading alternatives. This is somewhat natural, since the differences amongst the glazing and WWR values are also bigger than for shading (see Table 7). The shadings control strategies S0 and S1 are indicated as references, to assist the analysis of strategies S2 to S11. Overall results present a considerable dispersion in terms of energy consumption, with significant differences both between design alternatives and between the twelve shading control strategies. While the ranking of the alternatives is generally not significantly influenced by the change of control strategy, there are exceptions for strategies $\mathrm{S} 1$, S8 and S11, which all lead to shadings being active during most if not all of the time. Furthermore, the lower transmittances and wall areas are less sensitive to changes in control strategy. The two variants of the Lightswitch behavioral model produce significant ranking variations. These are justified by the fundamental differences in the algorithms: with the passive user mode, the shadings are fully deployed almost always throughout the year.

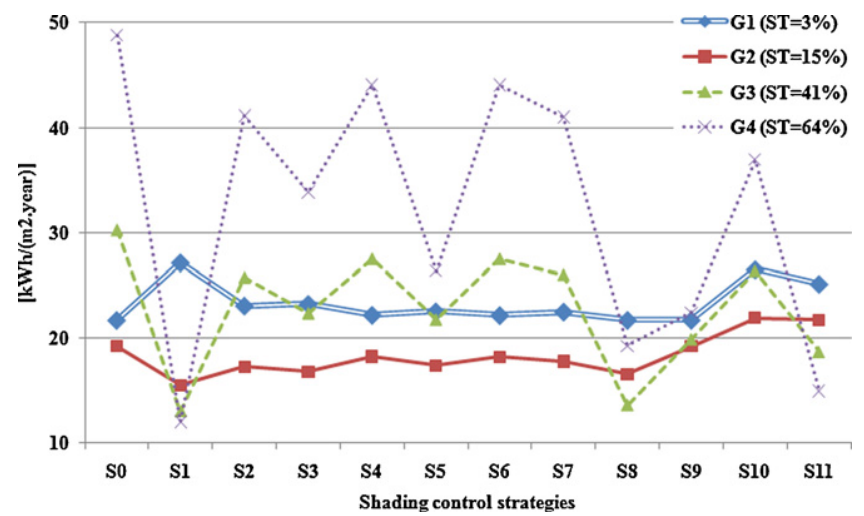

Fig. 3. Overall energy consumption for the four glazing alternatives in each of the 12 control strategies.

\subsection{Heating dominated scenario}

For the heating-dominated scenario, Fig. 7 shows the annual energy consumption of the office room, for the four glazing alternatives G1 to G4 under each of the twelve shading control strategies S0 to S11. Fig. 8 shows the results for the four shading alternatives presented in Table 7, while Fig. 9 shows the results for the four alternatives of WWR.

In this heating-dominated scenario, the ranking of design alternatives remains nearly constant across the different shading devices control strategies. The exceptions are the parametric studies related to the glazing and those related to the shading transmittance in those cases where the Lightswitch-active user model leads to some ranking inversion. The relatively small influence of the control strategies in this scenario is also confirmed by the fact that the energy consumption of each design alternative tends to be similar across the different control strategies. An explanation for this is the fact that the decrease in electric lighting needs decreases is partially offset by an increased need for heating.

\subsection{Balanced heating and cooling scenario}

The annual energy consumption of the office room for the case when heating and cooling energy needs are comparable, is shown in Fig. 10 for the four glazing alternatives. Fig. 11 shows the results for the four shading alternatives and Fig. 12 shows the results for the four WWR alternatives.

In this scenario, a reasonable number of ranking inversions occur across control strategies. The strategies S9 and S10 imply ranking variations if compared with the ranking resulting from the DGI based criteria (S4 to S7) and the Lightswitch criteria (S10), but are similar to the ranking of the seasonal-based strategies (S2 and S3). As in the previous scenarios, the influence of the control strategies on the energy consumption is more noticeable in the simulation of the glazing transmittance and window to wall ratio alternatives.

\section{Results analysis}

The main purpose of this case study is to assess the impact of the shadings control strategy (which supposedly mimics the human behavior) on the selection of transparent façade alternatives, when using the overall consumption of final energy for heating, cooling and lighting as the decision criteria. The results discussed in Section 5 do show that shading control strategies influence the choice of the best design alternative.

In order to analyze in a systematic way how the energy results and design options are affected by the control strategies and behavioral model, a set of indicators were computed (Table 10):Best alternative: percentage of occurrences (control strategies) in which the design alternative leads to the lowest energy consumption among the alternatives analyzed;Average ranking: average position index of each alterative considering all the control strategies (where, for each control strategy, the position index is 1 for the alternative which results in the lowest energy consumption and 4 the alternative which results in the highest energy consumption); Ranking ratio ( $\mathrm{max} / \mathrm{min})$ : ratio between the highest and lowest position index of each design alternative in the range of control strategies analyzed. A ranking ratio of 4.0 therefore means that the alternative has at least one control strategy in which it is the best design option and at least one control strategy in which is the worst option. A ranking ratio of 1.0 indicates that the ranking position of the alternative is constant through all the control strategies (regardless of ranking position). 


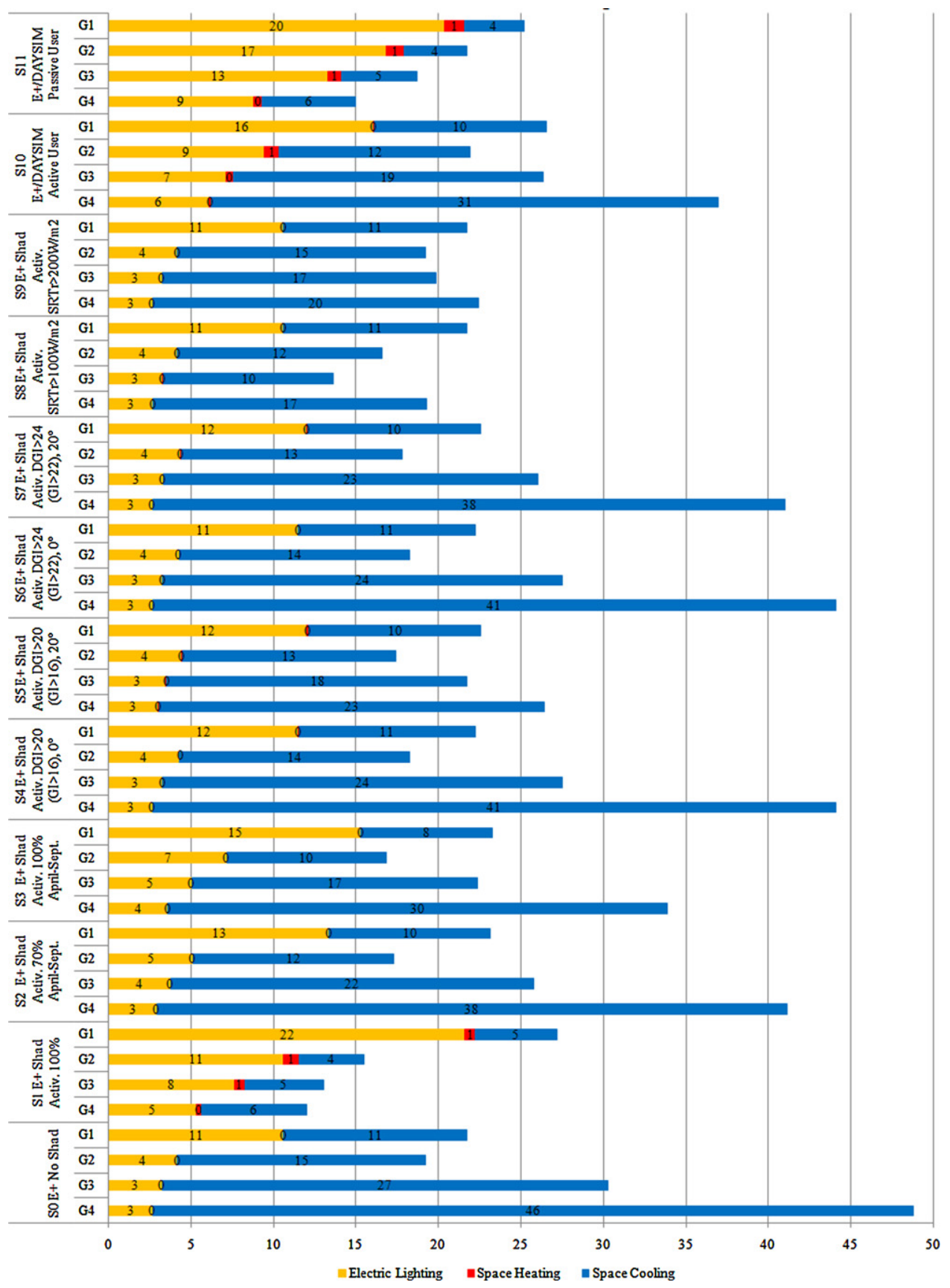

Fig. 4. Yearly energy consumption disaggregation for the four glazing transmittance alternatives.

Table 10 shows the indicators computed for each transparent envelope design alternative (glazing, shading and window-to-wall ratio). The calculation of the indicators did not take into consideration the shadings control strategies S0 and S1, since those strategies consider a permanent state of the shadings during all the year (they were studied for reference comparison only).

The indicators shown in Table 10 confirm that the energy-based merit of a given design alternative varies considerably with the control strategy assumed in the simulation. From the 9 sets of casestudies analyzed, only in one case (variation of the window-to-wall ratio in the heating dominated scenario) was there a design alternative (WWR4) which was always the best under any of the control strategies considered (S2 to S11). Furthermore, there is a significant number of design alternatives that have a ranking ratio of 4.0 , meaning that they are considered the best with some control strategy(ies) and the worst with some other control strategy(ies). The table however also reveals that the dispersion is much more significant in the "balanced heating and cooling" scenario than in the "cooling dominated scenario" and especially than in the "heating dominated scenario". In this latter one, the identification of the best alternative is almost consensual, with at least $90 \%$ of the control strategies leading to the same choice of best alternative. In the "balanced heating and cooling" scenario however there is a case in which the best alternative is not recognized as such by as much as $40 \%$ of the control strategies.

The fact that the use of different control strategies may lead to the choice of different design solutions is inconvenient from a practical point of view. It may also mean that many design solutions chosen today as energy efficient may in fact not be so. This justifies the need for further research in this area, which may lead 


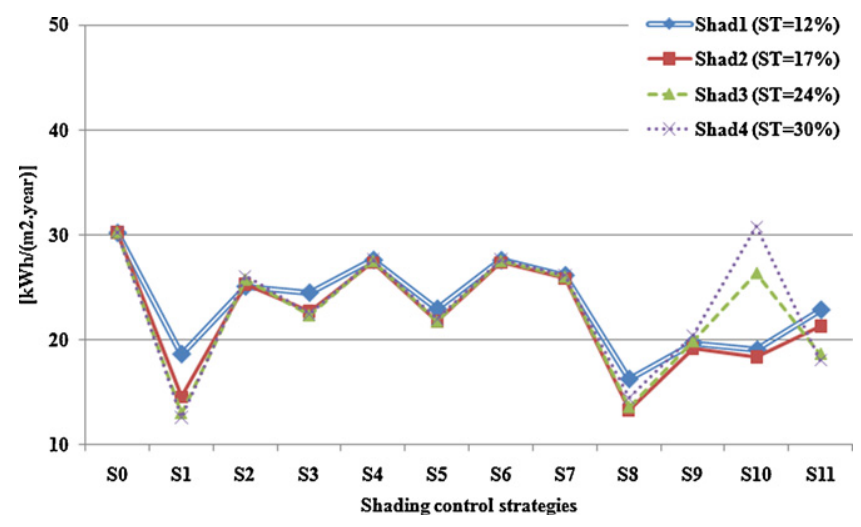

Fig. 5. Overall energy consumption for the four shading transmittance alternatives in each of the 12 control strategies.

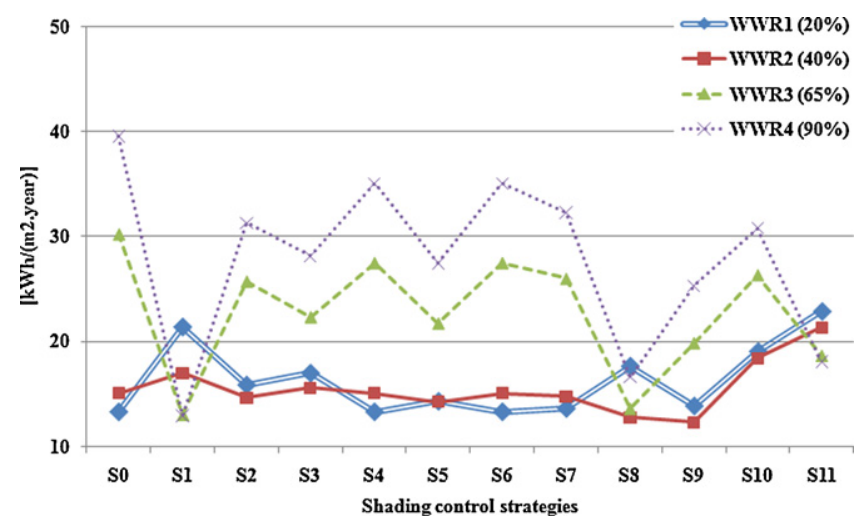

Fig. 6. Overall energy consumption for the four window to wall ratio alternatives in each of the 12 control strategies.

to behavior models with higher statistical significance so as to be widely acceptable as representative of occupants' behavior.

While such models are not available, and given that there is no scientifically solid indication that any of the behavioral models or control strategies is clearly better than the others, a possible solution recommendable from a methodological point of view would be to consider all the control strategies and choose the design alternative that ranks best according to the average. A variant of this method would be to choose a design alternative that ranks well and has a low ranking ratio (meaning that even if not guaranteeing the best performance, it would never lead to poor performance).

However, in the regular practice of building design, it is not convenient either - if feasible at all - to simulate the building with

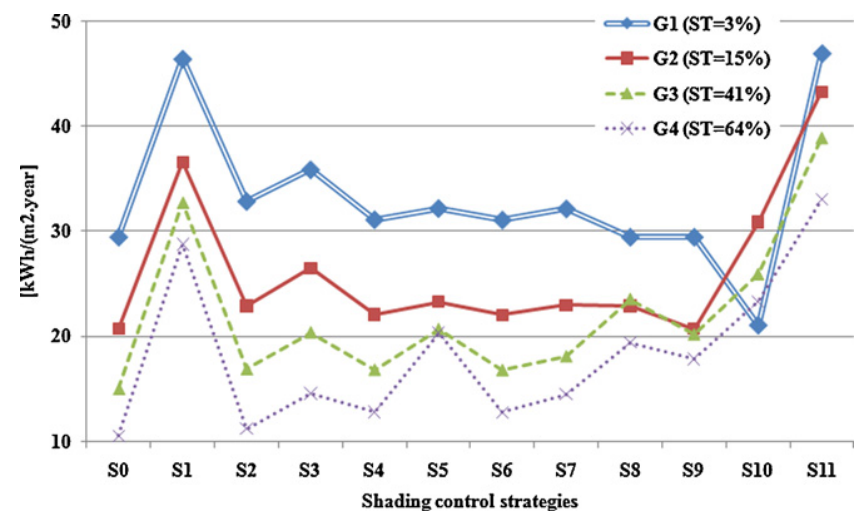

Fig. 7. Overall energy consumption for the four glazing transmittance alternatives in each of the 12 control strategies.

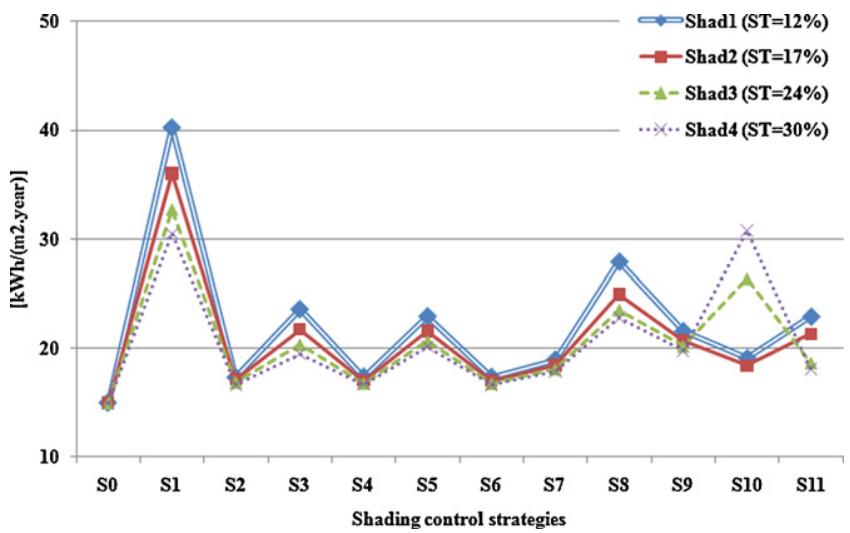

Fig. 8. Overall energy consumption for the four shading transmittance alternatives in each of the 12 control strategies.

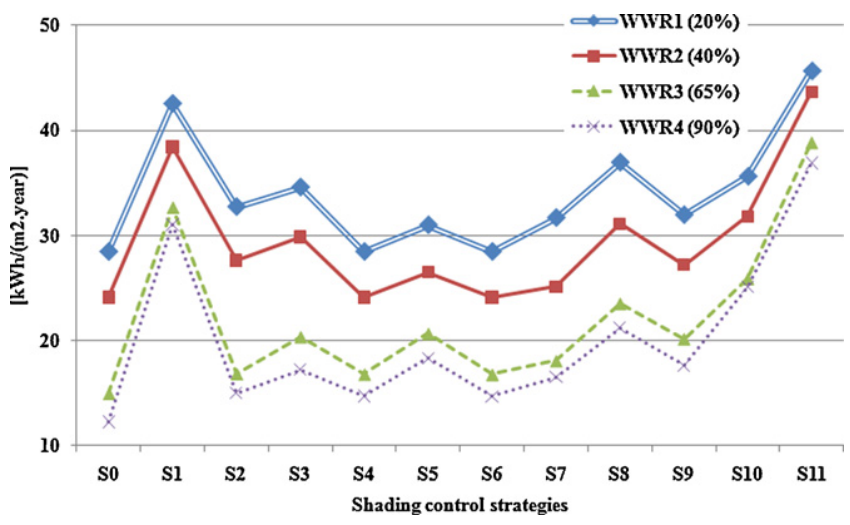

Fig. 9. Overall energy consumption for the four window to wall ratio alternatives in each of the control strategies.

different design solutions and different control strategies to perform a choice analysis after that. In fact, as referred to in Section 1 , considering one dynamic control pattern is already a procedure on the advanced side of the building design practice. Therefore, a search for the most reliable control strategy is required, i.e. are which would be most likely to lead to the choice of the same design alternative as the procedure based on the "best according to the average of the control strategies" would. This would indeed allow to simulate with just one control strategy instead of the nine control strategies initially considered. Table 11 provides a list of "the best according to the average" and "the best according to each individual control strategy". The last line of the table also shows the

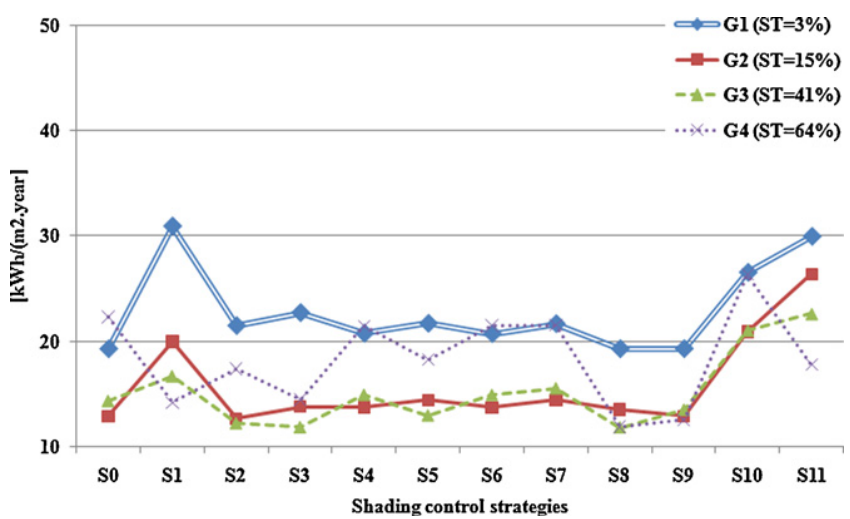

Fig. 10. Overall energy consumption for the four glazing transmittance alternatives in each of the control strategies alternatives. 


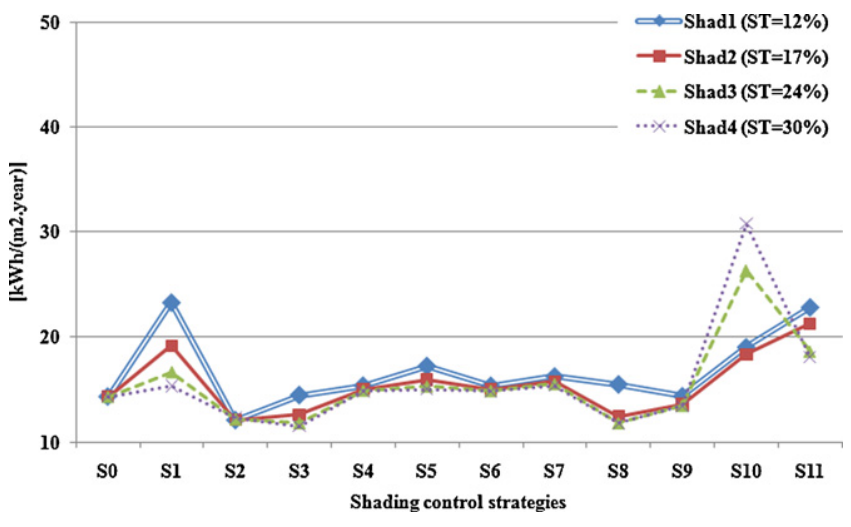

Fig. 11. Overall energy consumption for the four shading transmittance alternatives in each of the control strategies alternatives.

percentage of exact matches between the average ranking of the design alternative and the ranking according to each individual control strategy.

The results of Table 11 reveal that doing the building simulation with the control strategy S5 always leads to the choice of the design alternative that is also the best according to the average of all control strategies ( $100 \%$ match). As far as the ranking of all design alternatives is concerned (and not just the best), strategy $\mathrm{S} 5$ is also the one that better replicates the results obtained from the average of all control strategies, with a correspondence of $83 \%$. Fig. 13 illustrates in a graphical form the correlation between the rankings produced by strategies S5 and S11 and the average ranking from all

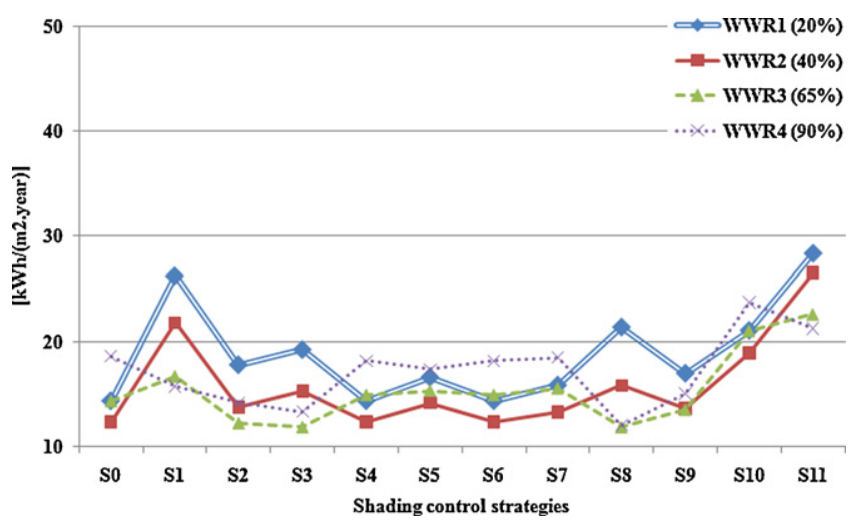

Fig. 12. Overall energy consumption for the four window to wall ratio alternatives in each of the control strategies.

control strategies. It again reinforces the conclusion that strategy S5 is the strategy that better mimics the choice of the average.

In summary, this section provides an analysis of the overall energy consumption resulting from the use of twelve shading control strategies from the point of view of transparent façade design choice. The design alternatives that would lead to the lowest energy consumption were identified, for each scenario, considering the average of the control strategies and the ranking dispersion associated to each strategy. Strategy S5 was shown as being capable of identifying design options that match the ranking for all control strategies in $83 \%$ of the cases.

Table 10

Indicators for each design alternative in the range of control strategies S2 to S11. Shadowed boxes show the alternatives with lower (best) average ranking.

\begin{tabular}{|c|c|c|c|c|c|c|c|c|c|}
\hline & \multicolumn{3}{|c|}{ Cooling dominated scenario } & \multicolumn{3}{|c|}{ Heating dominated scenario } & \multicolumn{3}{|c|}{ Balanced heating and cooling scenario } \\
\hline & $\begin{array}{l}\text { Best } \\
\text { alternative (\%) }\end{array}$ & $\begin{array}{l}\text { Average } \\
\text { ranking }\end{array}$ & $\begin{array}{l}\text { Ranking ratio } \\
(\max / \mathrm{min})\end{array}$ & $\begin{array}{l}\text { Best } \\
\text { alternative (\%) }\end{array}$ & $\begin{array}{l}\text { Average } \\
\text { ranking }\end{array}$ & $\begin{array}{l}\text { Ranking ratio } \\
(\max / \mathrm{min})\end{array}$ & $\begin{array}{l}\text { Best } \\
\text { alternative (\%) }\end{array}$ & $\begin{array}{l}\text { Average } \\
\text { ranking }\end{array}$ & $\begin{array}{l}\text { Ranking ratio } \\
(\max / \mathrm{min})\end{array}$ \\
\hline $\mathrm{G} 1(\mathrm{ST}=3 \%)$ & 0 & 2.8 & 2.0 & 10 & 3.7 & 4.0 & 0 & 3.8 & 1.3 \\
\hline $\mathrm{G} 2(\mathrm{ST}=15 \%)$ & 80 & 1.3 & 3.0 & 0 & 3.0 & 2.0 & 40 & 1.8 & 3.0 \\
\hline $\mathrm{G} 3(\mathrm{ST}=41 \%)$ & 10 & 2.3 & 3.0 & 0 & 2.2 & 1.5 & 40 & 1.7 & 3.0 \\
\hline $\mathrm{G} 4(\mathrm{ST}=64 \%)$ & 10 & 3.6 & 4.0 & 90 & 1.1 & 2.0 & 20 & 2.7 & 4.0 \\
\hline Shad1 $(\mathrm{ST}=12 \%)$ & 10 & 3.0 & 4.0 & 0 & 3.8 & 2.0 & 10 & 3.5 & 4.0 \\
\hline Shad2 $(\mathrm{ST}=17 \%)$ & 60 & 1.6 & 3.0 & 10 & 2.8 & 3.0 & 10 & 2.7 & 3.0 \\
\hline Shad3 $(\mathrm{ST}=24 \%)$ & 20 & 2.1 & 3.0 & 0 & 2.1 & 1.5 & 0 & 2.2 & 1.5 \\
\hline Shad4 $(\mathrm{ST}=30 \%)$ & 10 & 3.3 & 4.0 & 90 & 1.3 & 4.0 & 80 & 1.6 & 4.0 \\
\hline WWR1 (20\%) & 30 & 2.1 & 4.0 & 0 & 4.0 & 1.0 & 0 & 3.3 & 2.0 \\
\hline WWR2 (40\%) & 60 & 1.5 & 3.0 & 0 & 3.0 & 1.0 & 50 & 1.8 & 3.0 \\
\hline WWR3 (65\%) & 0 & 2.8 & 1.5 & 0 & 2.0 & 1.0 & 40 & 1.8 & 3.0 \\
\hline WWR4 (90\%) & 10 & 3.6 & 4.0 & 100 & 1.0 & 1.0 & 10 & 3.5 & 4.0 \\
\hline
\end{tabular}

Table 11

Comparison of the best alternative for each control strategy with the average best alternative.

\begin{tabular}{|c|c|c|c|c|c|c|c|c|c|c|c|c|}
\hline \multirow[t]{2}{*}{ Design alternatives } & \multirow[t]{2}{*}{ Opaque envelope scenarios } & \multirow[t]{2}{*}{ Best alternative } & \multicolumn{10}{|c|}{ Best alternatives for each control strategy } \\
\hline & & & $\mathrm{S} 2$ & S3 & S4 & S5 & S6 & S7 & S8 & S9 & S10 & S11 \\
\hline \multirow[t]{3}{*}{ Glazing types } & Cooling dominated & G2 & G2 & G2 & G2 & G2 & G2 & G2 & G3 & G2 & G2 & G4 \\
\hline & Heating dominated & G4 & G4 & G4 & G4 & G4 & G4 & G4 & G4 & G4 & G1 & G4 \\
\hline & Balanced cooling and heating & G3 & G3 & G3 & G2 & G3 & G2 & G2 & G3 & G4 & G2 & G4 \\
\hline \multirow{3}{*}{ Shading devices } & Cooling dominated & Shad2 & Shad2 & Shad4 & Shad3 & Shad2 & Shad3 & Shad3 & Shad3 & Shad1 & Shad1 & Shad3 \\
\hline & Heating dominated & Shad4 & Shad4 & Shad4 & Shad4 & Shad4 & Shad4 & Shad4 & Shad4 & Shad4 & Shad2 & Shad4 \\
\hline & Balanced cooling and heating & Shad4 & Shad1 & Shad4 & Shad4 & Shad4 & Shad4 & Shad4 & Shad4 & Shad4 & Shad2 & Shad4 \\
\hline \multirow[t]{3}{*}{ WWR } & Cooling dominated & WWR2 & WWR2 & WWR2 & WWR1 & WWR2 & WWR1 & WWR1 & WWR2 & WWR2 & WWR2 & WWR4 \\
\hline & Heating dominated & WWR4 & WWR4 & WWR4 & WWR4 & WWR4 & WWR4 & WWR4 & WWR4 & WWR4 & WWR4 & WWR4 \\
\hline & Balanced cooling and heating & WWR2 & WWR3 & WWR3 & WWR2 & WWR2 & WWR2 & WWR2 & WWR3 & WWR3 & WWR2 & WWR4 \\
\hline \multicolumn{3}{|c|}{ Percentage of matches with the best alternative } & $78 \%$ & $78 \%$ & $67 \%$ & $100 \%$ & $67 \%$ & $67 \%$ & $67 \%$ & $56 \%$ & $44 \%$ & $44 \%$ \\
\hline \multicolumn{3}{|c|}{$\begin{array}{l}\text { Percentage of matches of the average ranking with the design } \\
\text { alternative ranking }\end{array}$} & $61 \%$ & $69 \%$ & $67 \%$ & $83 \%$ & $67 \%$ & $78 \%$ & $44 \%$ & $69 \%$ & $47 \%$ & $56 \%$ \\
\hline
\end{tabular}



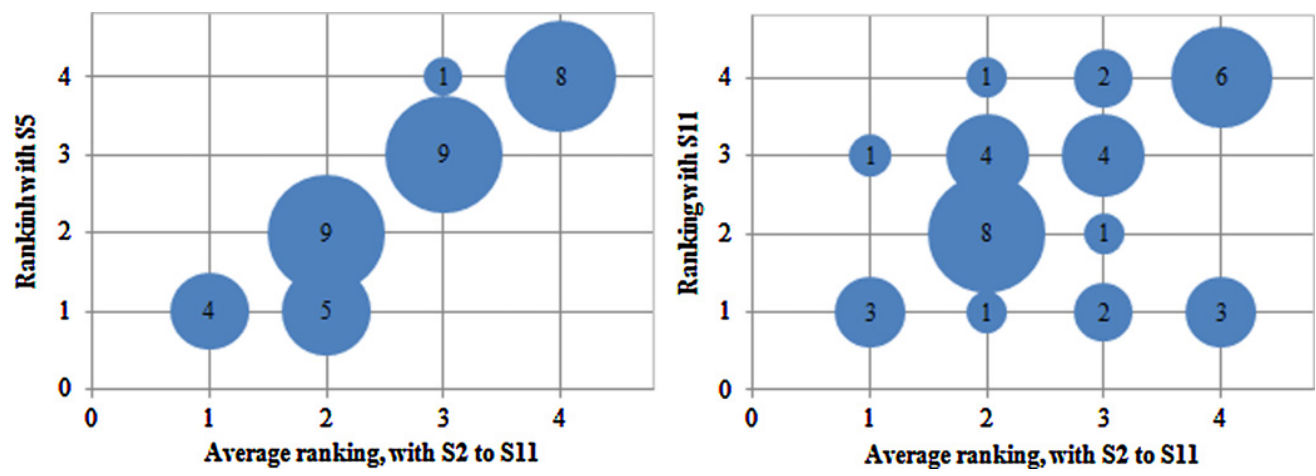

Fig. 13. Rankings with control strategies S2 and S11 vs. the average ranking (number of points overlapped indicated inside the circles).

\section{Conclusions}

This work started with a review establishing the human requirements for visual comfort in office buildings and the conditions that prompt building occupants to interact with the shading devices and with the electric lights. Numerous publications were found addressing the preferences of workers regarding lighting conditions in offices. There is a large range of reported parameters and even divergent recommendations among the different sources, though all claim to represent occupants preferences in an office building. Workplane illuminance is the most cited and studied parameter. Some other parameters referred to are surface) luminance (of windows, walls and ceiling), solar radiation entering the space and daylight discomfort indexes. However, these are not consistently presented in the literature, so further developments are necessary to reliably characterize occupants comfort preferences and response to lighting conditions in order to allow for robust comparisons. Regarding manual operation of window movable shadings or the change of the artificial lighting state, a significant number of occupant behavioral patterns and models were found too, with significant discrepancies among the bibliographic sources, especially in terms of shading devices control.

The simulation case study carried out to understand the impact of the use of different control patterns and behavioral models on the selection of transparent façade design options revealed that these directly influence the selection of design alternatives. The results showed that different behavioral models, even if all documented in the scientific literature, result in different choices of "best design alternative". This was remarkable on the office with balanced heating and cooling loads, and to some extent in the cooling-dominated and in the heating-dominated scenarios. Furthermore, the results show that even when not changing the merit order of design alternatives, the consideration of different control patterns and behavioral models has a significant impact on the computed energy performance.

Since different behavioral models lead to different choices of best design alternatives but there is no clear indication of which behavioral models are best, the option of choosing a design alternative based on average ranking computed with the results of all behavioral models was considered. The results show that the control strategy S5 (shading is active if DGI is higher than 20) is the one that, considered alone, replicates most reliably the choices made with the average ranking. Regarding the choice of the best design alternative, choosing with S5 alone always led to the same choice as choosing with the average. This result shall not be interpreted as proving that the behavioral model S5 is more realistic or valid than the others: it just means that it better represents the average of the whole group of models considered in terms of the results that they produce. Therefore, this study reinforces the need of further research focused on the identification of behavioral models with high statistical significance, developed from campaigns of post-occupancy monitoring of a large number of office buildings.

\section{Acknowledgments}

This research was supported by the Portuguese Foundation for Science and Technology (Fundação para a Ciência e Tecnologia $F C T$ ), under project PTDC/ENR/72597/2006 “Integrated evaluation of the impact of glazing and shading devices on the energy performance of Portuguese office buildings", hosted the Institute of Mechanical Engineering at the Faculty of Engineering of the University of Porto. The authors gratefully acknowledge the financial support of the Faculty of Engineering of the University of Porto, the Massachusetts Institute of Technology and the École Polytechnique Fédérale de Lausanne.

\section{References}

[1] L. Pérez-Lombard, J. Ortiz, C. Pout, A review on buildings energy consumption information, Energy and Buildings 40 (3) (2008) 394-398.

[2] F. Haldi, D. Robinson, A compreensive stochastic model of blind usage: theory and validation, in: Eleventh International IBPSA Conference, Glasgow, Scotland, 2009.

[3] D.R.G. Hunt, The use of artificial lighting in relation to daylight levels and occupancy, Building and Environment 14 (1) (1979) 21-33.

[4] C.F. Reinhart, K. Voss, Monitoring manual control of electric lighting and blinds, Lighting Research and Technology 35 (3) (2003) 243-260.

[5] L. Roche, E. Dewey, P. Littlefair, Occupant reactions to daylight in offices, Lighting Research and Technology (2000) 119-126.

[6] V. Inkarojrit, Balancing Comfort: Occupants' Control of Window Blinds in Private Offices, University of California, 2005.

[7] Y. Sutter, D. Dumortier, M. Fontoynont, The use of shading systems in VDU task offices: a pilot study, Energy and Buildings 38 (7) (2006) 780-789.

[8] E.S. Lee, S.E. Selkowitz, The design and evaluation of integrated envelope and lighting control strategies for commercial buildings, in: ASHRAE 1995 Winter Meeting, ASHRAE, Chicago, IL, 1995.

[9] J. Wienold, Dynamic daylight glare evaluation, in: Eleventh International IBPSA Conference, Glasgow, Scotland, 2009.

[10] M. Foster, T. Oreszczyn, Occupant control of passive systems: the use of Venetian blinds, Building and Environment 36 (2) (2001) 149-155.

[11] T. Inoue, et al., The development of an optimal control system for window shading devices based on investigations in office buildings, ASHRAE Transactions 104 (1988) 1034-1049.

[12] A. Mahdavi, C. Proglhof, User behavior and energy performance in buildings, in IEWT, in: Internationale Energiewirtschaftstagung, Wien, Austria, 2009.

[13] G.R. Newsham, Manual control of window blinds and electric lighting: implications for comfort and energy consumption, Indoor and Built Environment (1994) 135-144.

[14] S. Pigg, M. Eilers, J. Reed, Behavioral aspects of lighting and occupancy sensors in privates offices: a case study of a University office building, in: ACEEE 1996 Summer Study on Energy Efficiency in Buildings, vol. 8, 1996.

[15] RCCTE, Regulamento das Características do Comportamento Térmico dos Edifícios (Regulation of the Buildings Thermal Behaviour Characteristics), Ministry of Public Works, Tansportation and Communications, 2006.

[16] RSECE, Regulamento dos Sistemas Energéticos de Climatização em Edificios (Regulation of the Buildings Air Conditioning Energy Systems), Ministry of Public Works, Tansportation and Communications, 2006. 
[17] CEN, EN ISO 13790 Energy performance of buildings - calculation of energy use for space heating and cooling, European Commitee for Standardization, 2008.

[18] J.L.M. Hensen, R. Lamberts, Building Performance Simulation for Design and Operation, Taylor and Francis, 2011.

[19] LBNL, EnergyPlus Manual, Version 3.1, U.S. Department of Energy and Lawrence Berkeley National Laboratory, 2009.

[20] ESRU, Data Model Summary ESP-r Version 9 Series, Energy Systems Research Unit - University of Strathclyde, 2001.

[21] A. Fiksel, et al., Developments to the TRNSYS simulation program, Journal of Solar Energy Engineering 117 (2) (1995) 123-127, Other Information: PBD: May 1995: p. Medium: X; Size.

[22] C.F. Reinhart, Lightswitch-2002: a model for manual and automated control of electric lighting and blinds, Solar Energy 77 (1) (2004) 15-28.

[23] D. Bourgeois, C. Reinhart, I. Macdonald, Adding advanced behavioural models in whole building energy simulation: a study on the total energy impact of manual and automated lighting control, Energy and Buildings 38 (7) (2006) 814-823.

[24] P.R. Boyce, N.H. Eklund, Evaluating lighting quality, in: 3rd European Conference on Energy-Efficient Lighting, Newcastle-upon-Tyne, UK, 1995.

[25] M.-C. Dubois, Shading devices and daylight quality: an evaluation based on simple performance indicators, Lighting Research and Technology 35 (1) (2003) 61-74.

[26] G.R. Newsham, J.A. Veitch, Lighting quality recommendations for VDT offices: a new method of derivation, Lighting Research and Technology (2001) 97-113.

[27] M.S. Rea, Lighting Handbook: Reference and Application, Ninth Edition ed., Illuminating Engineering Society of North America, New York, 2000.

[28] J.A. Veitch, Lighting guidelines from lighting quality research, in: CIBSE/ILE Lighting 2000 Conference, York, UK, 2000.

[29] J.A. Veitch, G.R. Newsham, Quantifying lighting quality based on experimental investigations of end user performance and preference, in: 3rd European Conference on Energy-Efficient Lighting, Newcastle-upon-Tyne, UK, 1995.

[30] J.A. Veitch, G.R. Newsham, Determinants of lighting quality II: research and recommendations, in: 104th Annual Convention of the American Psycological Association, Toronto, ON, Canada, 1996.

[31] M. Velds, Assessment of Lighting Quality in Office Buildings with Daylighting Systems, Technical University of Delft, 2000.

[32] P.R. Boyce, N.H. Eklund, S.N. Simpson, Individual lighting control: task performance, mood, and illuminance, Journal of the Illuminating Engineering Society (2000) 131-142.

[33] P.R. Boyce, et al., Occupant use of switching and dimming controls in offices, Lighting Research and Technology (2006) 358-376.

[34] CEN, EN 12464-1 Lighting of Work Places - Part 1: Indoor Work Places, European Commitee for Standardization, 2002

[35] CIBSE, Code for Lighting, Butterworth-Heinemann Publications, London, 2002.

[36] S. Escuyer, M. Fontoynont, Lighting controls: a field study of office workers' reactions, Lighting Research and Technology (2001) 77-94.

[37] L. Roche, Summertime performance of an automated lighting and blinds control system, Lighting Research and Technology 34 (1) (2002) 11-25.

[38] T. Moore, D.J. Carter, A.I. Slater, User attitudes toward occupant controlled office lighting, Lighting Research and Technology. (2002) 207-216.

[39] K. Fisekis, et al., Prediction of discomfort glare from windows, Lighting Research and Technology 35 (4) (2003) 360-369.

[40] M. Luckiesh, S.K. Guth, Brightness in visual field at borderline between comfort and discomfort (BCD), in: National Technical Conference of the Illumination Engineering Society, French Lick, Indiana, 1949.

[41] W. Platzer, Architectural and Technical Guidelines - Handbook for the Use of Switchable Facades Technology, Fraunhofer Institute for Solar Energy Systems, Freiburg, 2003.

[42] CEN, EN 14501 Blinds and Shutters - Thermal and Visual Comfort Performance Characteristics and Classification, European Commitee for Standardization, 2005.
[43] S.K. Guth, Computing visual comfort ratings for a specific interior lighting installation, in: National Technical Conference of the Illumination Engineering Society, Mineapolis, 1966.

[44] W.K.E. Osterhaus, Discomfort glare assessment and prevention for daylight applications in office environments, Solar Energy 79 (2) (2005) 140-158.

[45] R.G. Hopkinson, Glare from daylighting in buildings, Applied Ergonomics 3 (1972) 206-215

[46] L. Bellia, et al., Daylight glare: a review of discomfort indexes, in: Visual Quality and Energy Efficiency in Indoor Lighting: Today for Tomorrow, Rome, 2008

[47] A.A. Nazzal, A new daylight glare evaluation method: introduction of the monitoring protocol and calculation method, Energy and Buildings 33 (3) (2001) 257-265.

[48] A.A. Nazzal, A new evaluation method for daylight discomfort glare, International Journal of Industrial Ergonomics 35 (4) (2005) 295-306.

[49] J. Wienold, J. Christoffersen, Evaluation methods and development of a new glare prediction model for daylight environments with the use of CCD cameras, Energy and Buildings 38 (7) (2006) 743-757.

[50] F. Cantin, Évaluation de la qualité lumineuse d'un environnement de travail éclairé naturellement: Le cas de l'édifice de la CDP de Montréal, in: École d'Architecture, Université Laval, Québec, 2008.

[51] C. Cuttle, Lighting by Design, Architectural Press, Oxford, 2008.

[52] J.A. Love, The evolution of performance indicators for the evaluation of daylighting systems, in: Industry Applications Society Annual Meeting, Houston, TX, USA, 1992, pp. 1830-1836.

[53] P. Boyce, C. Hunter, O. Howlett, The Benefits of Daylight Through Windows, Lighting Research Center - Rensselaer Polytechnic Institute, 2003.

[54] M.-C. Dubois, F. Cantin, K. Johnsen, The effect of coated glazing on visual perception: a pilot study using scalea models, Lighting Research and Technology 39 (3) (2007) 283-304.

[55] H. Arsenault, M. Héber, M.-C. Dubois, Glazing colour types, daylight quality, arousal and switch-on patterns for electric lights, in: CISBAT 2011, Lausanne, Switzerland, 2011.

[56] L. Heschong, et al., Windows and Offices: A Study of Office Worker Performance and the Indoor Environment, California Energy Commission, 2003.

[57] H. Hellinga, T.d. Bruin-Hordijk, A new method for the analysis of daylight access and view out, in Lux Europa 2009, in: 11th European Lighting Conference, Istanbul, Turkey, 2009.

[58] K.M.J. Farley, J.A. Veitch, A Room with a View; a Review of the Effects of Windows on Work and Well-being, Institute for Research in Construction, Ottawa, 2001.

[59] N. Tuaycharoen, P.R. Tregenza, View and discomfort glare from windows, Lighting Research and Technology 39 (2) (2007) 185-198.

[60] A. Mahdavi, C. Proglhof, Toward empirically-based models of peopleǐs presence and actions in buildings, in: Eleventh International IBPSA Conference, Glasgow, Scotland, 2009.

[61] D.R.G. Hunt, V.H.C. Crisp, Lighting controls: their current use and possible improvement, International Journal of Energy Research 2 (4) (1978) 343-374.

[62] Saint-Gobain, Manual do Vidro, Saint-Gobain Glass, 2000 (in Portuguese).

[63] D.v. Dijk, WIS Version 2.0.1 User Guide, TNO Building and Construction Research, 2003.

[64] G.R. Newsham, A. Mahdavi, I. Beausoleil-Morrison, Lightswitch: a stochastic model for predicting office lighting energy consumption, in: 3rd European Conference on Energy-Efficient Lighting, Newcastle upon Tyne, England, 1995.

[65] C.F. Reinhart, Tutorial on the Use of Daysim Simulation for Sustainable Design, National Research Council Canada (IRC), 2006.

[66] F.C. Winkelmann, Daylighting Simulation in the DOE-2, Lawrence Berkeley Laboratory - University of California, 1983

[67] F.C. Winkelmann, S. Selkowitz, Daylighting simulation in the DOE-2 building energy analysis program, Energy and Buildings 8 (4) (1985) 271-286. 